\title{
An Identification Method for the Unbalance Parameters of a Rotor-Bearing System
}

\author{
Wengui Mao,, ${ }^{1,2,3}$ Guiping Liu,, Jianhua Li, ${ }^{1,3}$ and Jie Liu ${ }^{2}$ \\ ${ }^{1}$ College of Mechanical Engineering, Hunan Institute of Engineering, Xiangtan 411101, China \\ ${ }^{2}$ State Key Laboratory of Advanced Design and Manufacturing for Vehicle Body, College of Mechanical and Vehicle Engineering, \\ Hunan University, Changsha 410082, China \\ ${ }^{3}$ Hunan Province Cooperative Innovation Center for Wind Power Equipment and Energy Conversion, Hunan Institute of Engineering, \\ Xiangtan 411101, China \\ Correspondence should be addressed to Wengui Mao; mwglikai@163.com
}

Received 27 July 2015; Revised 7 October 2015; Accepted 13 October 2015

Academic Editor: Salvatore Strano

Copyright (c) 2016 Wengui Mao et al. This is an open access article distributed under the Creative Commons Attribution License, which permits unrestricted use, distribution, and reproduction in any medium, provided the original work is properly cited.

\begin{abstract}
This paper is to be submitting an identification method for the unbalance parameters of a rotor-bearing system. In the method, the unbalance parameters identification problem is formulated as the unbalance force reconstruction which belongs to solving deconvolution problem, in which the unbalance force is expressed in the time domain. The unbalance response is expressed by the convolution integral of Green's function and the unbalance force. In order to avoid the unstable solution arising from the noisy responses and the deconvolution, a regularization method is adopted to stabilize the solution. Meanwhile, a searching of the sensitive measured point has also been carried out to confirm the robustness of the method. Numerical example and a test rig have been used to illustrate the proposed method.
\end{abstract}

\section{Introduction}

In rotating machinery systems, undesirable vibration is caused by unbalance parameters which are inevitable due to asymmetric geometry, material inhomogeneity, manufacturing tolerances, and elastic deformations of the flexible rotor shaft during operations. However, reliable estimates of unbalance parameters are difficult to obtain with theoretical models due to many impact factors. On the contrary, identification methods based on experimental data from actual test conditions provide reliable unbalance characterization which avoids the complexity of exact system modeling and analysis. It is for this reason that designers of rotating machinery mostly rely on the experimentally identified unbalance parameters in their instability analysis.

Over the years, identification of the unbalance parameters is fundamental for the balance of a rotor-bearing system. The method of mechanical balancing is adopted to isolate the vibration arising from the inherent rotor unbalance, in which small amounts of unbalance mass are added and/or removed at specific locations to gain a satisfactory state of balance for a machine. Thus, identification technology of the unbalance parameters is improved with the development of the balancing technology [1-6]. Nevertheless, using trial weights to find the unbalance parameters in balancing field is often a timeconsuming and expensive task because of requiring many machinery start-ups. These rotating machines have a high capital cost and hence the trend in the unbalance parameters identified is to reduce the number of test runs required.

Some researchers introduced optimization algorithm and inversed technology to identify the unbalance parameters. Han et al. [7] identified the unbalance parameters of a rotor-bearing system based on Kriging surrogate model and evolutionary algorithm. Tiwari and Chakravarthy [8] presented a method to identify the unbalance parameters based on the measured force response. Edwards et al. $[3,9,10]$ considered the identification of the unbalance parameters based on the unbalance force in many works. De Queiroz [11] presented an unbalance force identification method to identify the unbalance parameters based on the measured 
harmonic response. In these methods, unbalance parameters are all ascribed to the unbalance force. The unbalance force is identified through measured response. However, the inverse problem of the unbalance force identification is commonly ill posed [12] and noisy responses will induce serious errors in the process of identifying the unbalance parameters. So developing some inversed techniques for avoiding the ill posed problem has become the mainstream methods $[13,14]$.

In the paper, the unbalance parameters identification is formulated as the unbalance force identification problem. An identification method for the unbalance parameters of a rotor-bearing system based on the unbalance force reconstruction is proposed to avoid the ill condition from the measured response and the deconvolution. In the method, the unbalance force acting on rotor-bearing systems is to be determined based on the measured time domain responses coming from transient analysis. The ill condition problem of the unbalance force reconstruction will be treated by the Tikhonov regularization which can provide efficient and numerically stable solutions. In order to search for the sensitive measured point, the Finite Element Method (FEM) is adopted for the forward analysis to obtain transient responses with assumed unbalance parameters. Finally, numerical example and a test rig have been used to illustrate the identification method for the unbalance parameters.

\section{Theories of the Unbalance Force Reconstruction}

2.1. Dynamical Model of Rotor-Bearing Systems with the Unbalance Force. The linearized motion equation of rotorbearing systems is expressed as

$$
\mathbf{M} \ddot{\mathbf{q}}+(\omega \mathbf{T}+\mathbf{D}) \dot{\mathbf{q}}+\mathbf{K q}=\mathbf{F},
$$

where $\omega$ is the shaft rotational speed, $\mathbf{F}$ is the unbalance force vector, $\mathbf{q}$ is the transient response vector, and $\mathbf{M}, \mathbf{T}, \mathbf{D}$, and $\mathbf{K}$ are the mass, gyroscopic, damping, and stiffness matrices.

In the paper, the rotor model of rotor-bearing systems is built by Euler beam elements and the consistent matrices' approach described by Genta [15] and the bearing dynamic parameters of the sliding bearing can be obtained based on the full Navier-Stokes equation [16, 17] or Reynolds equation $[18,19]$.

In fact, the unbalance force caused by the unbalance parameters can be structured by

$$
\begin{aligned}
& \mathbf{F}=\left(\begin{array}{l}
f_{x} \\
f_{y}
\end{array}\right)=\left[\begin{array}{cc}
\cos \omega t & -\sin \omega t \\
\sin \omega t & \cos \omega t
\end{array}\right]\left(\begin{array}{c}
A \cos \varphi \\
A \sin \varphi
\end{array}\right), \\
& A=m e \omega^{2},
\end{aligned}
$$

where $t$ is time, the unbalance magnitude of $m$ and the unbalance phase $\varphi$ defined relative to the shaft marker are the unbalance parameters, and $e$ is a radius of the chosen reference plane.

In many practical situations, the radius $e$ is predetermined to some arbitrary chosen reference plane; hence $e$ is known. The unbalance parameters $(m, \varphi)$ can be determined uniquely by the unbalance force $\left(f_{x}, f_{y}\right)$. Thus, the unbalance parameters identification can be formulated into the unbalance force reconstruction.

2.2. The Unbalance Force Reconstruction. Considering the system that acted on the unbalance force is a liner and timeinvariant system, the transient response of (1) at a direction $(x)$ by a single unbalance force can also be expressed by a convolution integral function that is multiplied by the unbalance force function and the corresponding Green's kernel in time domain by Liu and Han [20] and Liu et al. [21], which is expressed by

$$
u(x, t)=\int_{0}^{t} g(x, t-\tau) f(\tau) d \tau
$$

where $u(x, t)$ is the transient response in $x$ direction, $g(x, t)$ is the response of a unit pulse of rotor-bearing systems, named the corresponding Green's function, and $f(t)$ is the time history of the unbalance force acting on the rotor-bearing system which needs to be identified.

When this convolution integral in the time domain is discretized to $Q$ evenly spaced sample points, (3) can be expressed by a matrix form of

$$
\begin{gathered}
{\left[\begin{array}{c}
u\left(x, t_{1}\right) \\
u\left(x, t_{2}\right) \\
\vdots \\
u\left(x, t_{\mathrm{Q}}\right)
\end{array}\right]} \\
=\left[\begin{array}{cccc}
g\left(t_{1}\right) & 0 & \cdots & 0 \\
g\left(t_{2}\right) & g\left(t_{1}\right) & \cdots & 0 \\
\vdots & \vdots & \ddots & \vdots \\
g\left(t_{\mathrm{Q}}\right) & g\left(t_{\mathrm{Q}-1}\right) & \cdots & g\left(t_{1}\right)
\end{array}\right]\left[\begin{array}{c}
f\left(t_{0}\right) \\
f\left(t_{1}\right) \\
\vdots \\
f\left(t_{\mathrm{Q}-1}\right)
\end{array}\right] \Delta t,
\end{gathered}
$$

where $u\left(x, t_{j}\right), g\left(t_{j}\right)$, and $f\left(t_{j}\right)$ are the displacement, Green's function, and unbalance force at the time $t_{j}=j \Delta t,(j=$ $0,1, \ldots, Q)$, respectively. $\Delta t$ is the time interval.

Equation (4) can be equivalent to

$$
\mathbf{U}=\mathbf{G} \cdot \mathbf{F} \text {. }
$$

Because the rotor-bearing system is linear, the total displacement can be gained by the linear superposition method. When a rotor-bearing system is acted on multisource unbalance forces in two radial directions ( $x$ and $y$ ), 
the identification problem of multisource unbalance forces is expressed by

$$
\begin{aligned}
& {\left[\begin{array}{c}
\mathbf{U}^{(x 1)} \\
\mathbf{U}^{(y 1)} \\
\vdots \\
\mathbf{U}^{(x M)} \\
\mathbf{U}^{(y M)}
\end{array}\right]} \\
& =\left[\begin{array}{ccccc}
\mathbf{G}^{(x 1 x 1)} & \mathbf{G}^{(x 1 y 1)} & \ldots & \mathbf{G}^{(x 1 x N)} & \mathbf{G}^{(x 1 y N)} \\
\mathbf{G}^{(y 1 x 1)} & \mathbf{G}^{(y 1 y 1)} & \ldots & \mathbf{G}^{(y 1 x N)} & \mathbf{G}^{(y 1 y N)} \\
\vdots & \vdots & \ddots & \vdots & \vdots \\
\mathbf{G}^{(x M x 1)} & \mathbf{G}^{(x M y 1)} & \ldots & \mathbf{G}^{(x M x N)} & \mathbf{G}^{(x M y N)} \\
\mathbf{G}^{(y M x 1)} & \mathbf{G}^{(y M y 1)} & \ldots & \mathbf{G}^{(y M x N)} & \mathbf{G}^{(y M y N)}
\end{array}\right]\left[\begin{array}{c}
\mathbf{F}^{(x 1)} \\
\mathbf{F}^{(y 1)} \\
\vdots \\
\mathbf{F}^{(x N)} \\
\mathbf{F}^{(y N)}
\end{array}\right],
\end{aligned}
$$

where $M$ is the number of points used to measure displacement and $N$ is the number of unbalance forces sources. $\mathbf{U}^{(y m)},(m=1,2, \ldots, M)$, and $\mathbf{F}^{(y n)},(n=1,2, \ldots, N)$ are the $m$ th measured displacement and the $n$th unbalance force, respectively, and $\mathbf{G}^{(y m y n)}$ is Green's function matrix coming from the $n$th unbalance force to the $m$ th measured displacement.

For presentation purposes, (4) and (6) are shown using the matrix form as (5) uniformly.

In order to reconstruct $\mathbf{F}$ from $\mathbf{U}$ in real rotor-bearing systems in the time domain, the transient response $\mathbf{U}$ and Green's function G need to be known. Usually, in actual project, the transient response $\mathbf{U}$ can be measured by sensors. Green's function $\mathbf{G}$ can be obtained by some numerical computation method. However, the measured response often contains noise. It is one major reason that the problem of identifying the unbalance force is usually ill posed. The ill posed problem can be dealt with through A Tikhonov regularization method $[22,23]$.

2.3. Regularization. In general, the identified unbalance force is inaccurate because of the noise data of measured displacement which can produce amplified errors of identified result in inverse problems. And Green's matrix is sensitive to these errors.

Considering the noise data of measured displacement, (5) can be expressed as follows:

$$
\mathbf{U}_{\delta}=\mathbf{G} \cdot \mathbf{F}+\boldsymbol{\delta},
$$

where $\mathbf{U}_{\delta}$ is measured displacement containing noise data. $\mathbf{F}$ is theoretical value of identified unbalance force. $\boldsymbol{\delta}$ is the noise data of measured displacement.

When there is no additional information in the process of unbalanced force identification, a singular value decomposition (SVD) in the method of regularization is used to deal with the noise data of measured displacement [20]. Then the decomposition of $\mathbf{G}$ is as follows:

$$
\mathbf{G}=\mathbf{W} \Omega \mathbf{V}^{T}=\sum_{i=1}^{k} \mathbf{w}_{i} \boldsymbol{\sigma}_{i} \mathbf{v}_{i}^{T},
$$

where $\mathbf{W}=\left[\begin{array}{llll}\mathbf{w}_{1} & \mathbf{w}_{2} & \cdots & \mathbf{w}_{k}\end{array}\right], \mathbf{V}=\left[\begin{array}{llll}\mathbf{v}_{1} & \mathbf{v}_{2} & \cdots & \mathbf{w}_{k}\end{array}\right]$ are matrices with orthonormal columns, $\mathbf{W}^{T} \mathbf{W}=\mathbf{V}^{T} \mathbf{V}=\mathbf{I}_{k}$ and in which $\Omega=\operatorname{Diag}\left(\sigma_{i}\right),(i=1,2, \ldots, k)$, has nonnegative diagonal singular values appearing in nonincreasing order. In addition, this decomposition is particularly helpful because it can give a formulation of the identified unbalance force:

$$
\begin{aligned}
\widetilde{\mathbf{F}} & =\mathbf{G}^{-1} \mathbf{U}_{\delta}=\operatorname{VDiag}\left(\boldsymbol{\sigma}_{i}^{-1}\right) \mathbf{W}^{T} \mathbf{U}_{\delta} \\
& =\mathbf{F}+\sum_{i=1}^{k} \boldsymbol{\sigma}_{i}^{-1}\left(\mathbf{w}_{i}^{T} \boldsymbol{\delta}\right) \mathbf{v}_{i} .
\end{aligned}
$$

Through (9), it showed that the identified unbalance force will be affected by the noise data of measured displacement $\delta$ which can be dealt with by the small singular value $\boldsymbol{\sigma}_{i}$. In the method of regularization, the value $\sigma_{i}^{-1}$ is multiplied by a filter function $f\left(\alpha, \sigma_{i}\right)$ to overcome this problem. Then the stable and approximate solution $\widetilde{\mathbf{F}}_{\alpha}$ for the unknown unbalance force can be obtained by

$$
\begin{aligned}
\widetilde{\mathbf{F}} & =\mathbf{G}^{\alpha} \cdot \mathbf{U}_{\delta}=\operatorname{VDiag}\left(f\left(\alpha, \sigma_{i}\right) \boldsymbol{\sigma}_{i}^{-1}\right) \mathbf{W}^{T} \mathbf{U}_{\delta} \\
& =\sum_{i=1}^{k} f\left(\alpha, \sigma_{i}\right) \boldsymbol{\sigma}_{i}^{-1}\left(\mathbf{w}_{i}^{T} \mathbf{U}_{\delta}\right) \mathbf{v}_{i} .
\end{aligned}
$$

If the filter function is selected by (11), (10) will be expressed by (12):

$$
\begin{aligned}
f(\alpha, \sigma) & =1-\frac{4}{\pi} \arctan \left(e^{-\sigma / \alpha}\right), \\
\widetilde{\mathbf{F}}_{\alpha} & =\sum_{i=1}^{k}\left(1-\frac{4}{\pi} \arctan \left(e^{-\sigma / \alpha}\right)\right) \boldsymbol{\sigma}_{i}^{-1}\left(\mathbf{w}_{i}^{T} \mathbf{U}_{\delta}\right) \mathbf{v}_{i} \\
& =\left(\mathbf{G}^{T} \mathbf{G}+\alpha \mathbf{I}\right)^{-1} \mathbf{G}^{T} \mathbf{U}_{\delta} .
\end{aligned}
$$

\section{Solving Strategy}

In actual practice, the ill posed inverse problem can be dealt with by regularization described above. It is often effective to select effective measurements that are sensitive to the parameter variation to avoid the ill posedness. The proposed solving strategy for identifying the unbalance parameters of a rotor-bearing system based on the unbalance force reconstruction is outlined in Figure 1.

In this method, firstly, transient response of numerical calculation based on the FEM can be obtained with assumed unbalance parameters and displacement responses numerically generated are treated as actual measurements after adding the measurement noise. Numerical simulation model of rotor-bearing systems is used to search for a strong correlation point between the displacement response and the unbalanced force by comparison of identified unbalance parameters with the assumed ones. Then, the response of a unit pulse generated numerically and the experimental response of the test rig at reference measured points are used to gain the unbalance force reconstruction, and the regularization method is adopted to deal with ill posedness. 


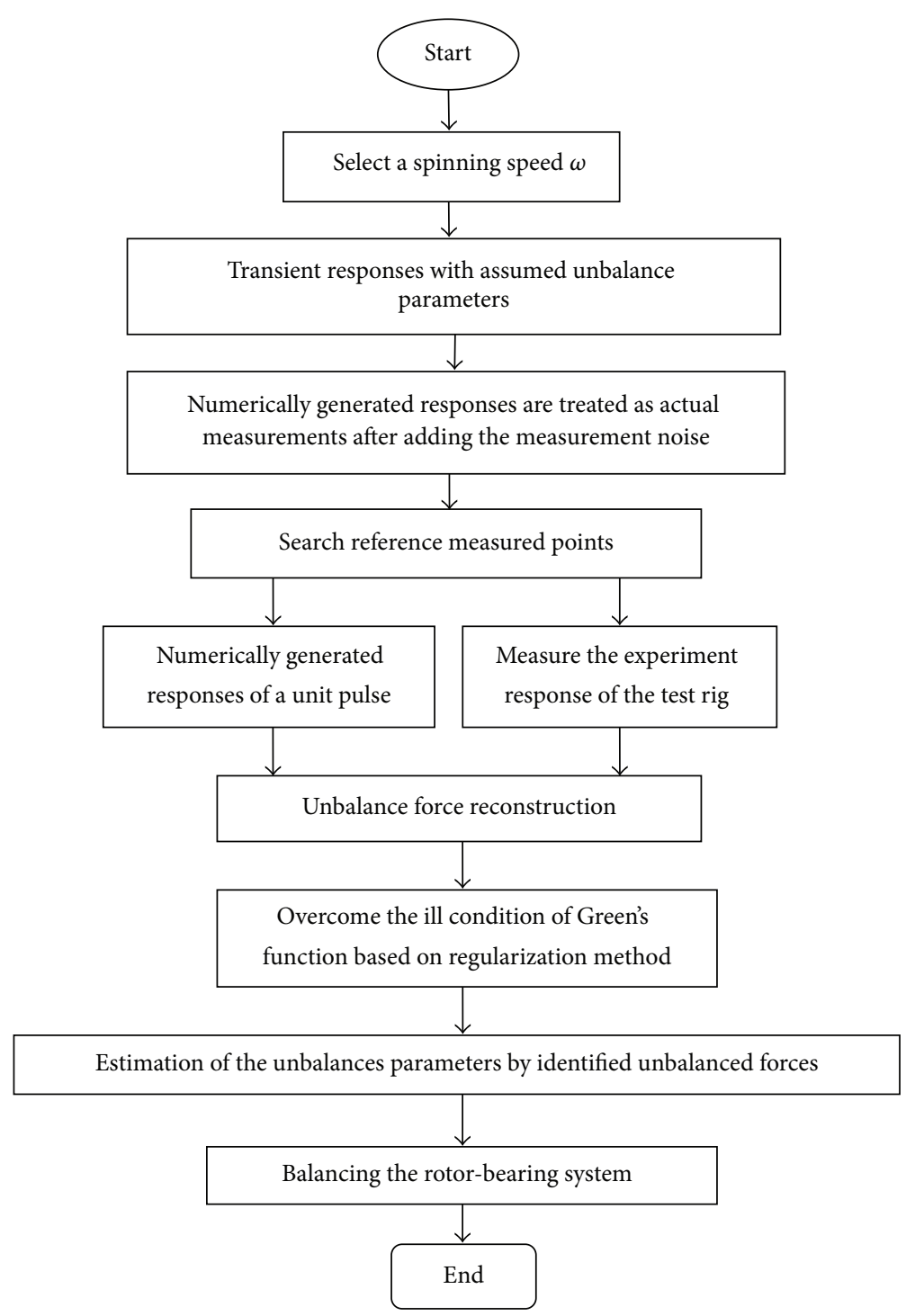

FIgURE 1: The identification method for the unbalance parameters of a rotor-bearing system.

Finally, the unbalance parameters of the rotor-bearing system are identified from the unbalance force reconstruction based on the experimental data.

\section{Numerical Simulation}

Before applying the proposed method to the actual test data, using the direct numerical simulation to search for strong correlation point between the displacement response and the unbalanced force, meanwhile the numerical simulation is used to examine the reliability and accuracy of the proposed method. A numerical simulation coming from the literature [1] is performed, and Figure 2 shows the parameters and the FEM model. The bearing dynamic parameters of the sliding bearing and the structural parameters of the numerical model are listed in Table 1. The numerical model is subdivided into 20 elements consisting of 21 nodes with two disks at nodes 6 and 16. The assumed unbalance parameters are $4.50 \mathrm{~g}$ at $30^{\circ}$ in disc 1 and $2.20 \mathrm{~g}$ at $60^{\circ}$ in disc 2 .

The displacement responses in the time domain at nodes 2 and 20 are collected at $4000 \mathrm{rpm}$ by using assumed unbalance parameters. 5\% Gaussian noise is added in the displacement responses to simulate the actual measurement noise and to check the robustness of the proposed method for identifying the unbalance parameters. And the identification method was proposed to determine the multisource unbalance forces. The identified unbalance parameters will be compared with the corresponding actual unbalance parameters and the unbalance parameters identified by the impulse response in the literature [1] to check the effectiveness of the proposed method.

The comparison results of the numerical simulation in Figures 3 and 4 show that the unbalance forces identified by the proposed method are in accord with the assumed and the literature's ones. The identified unbalance parameter is 


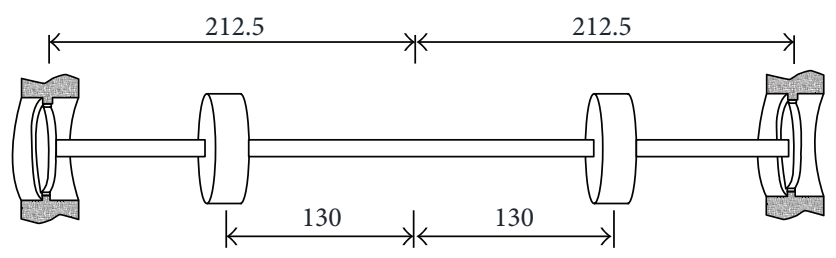

(a) Statically determinate rotor model

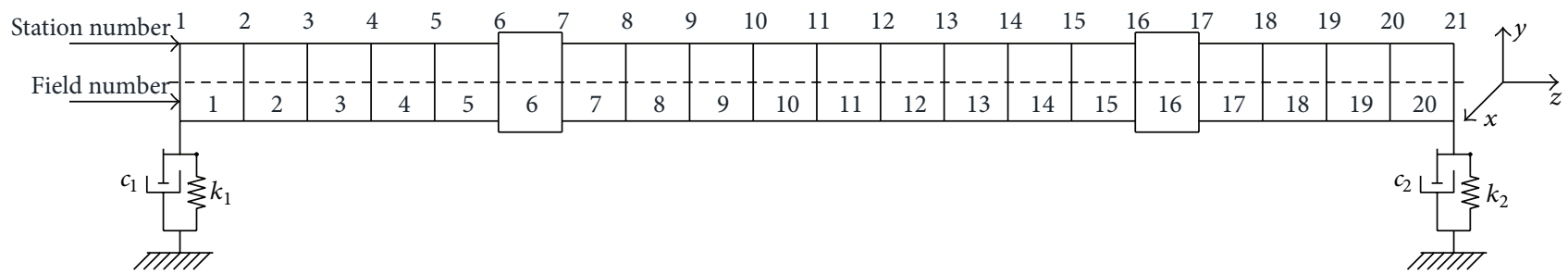

(b) The FEM model

FIGURE 2: The model for the numerical simulation.

TABLE 1: Parameters of the numerical model.

\begin{tabular}{|c|c|c|c|c|}
\hline Parts & \multicolumn{2}{|c|}{ Parameters } & \multicolumn{2}{|c|}{ Specifications } \\
\hline \multirow{5}{*}{ Shaft } & \multicolumn{2}{|c|}{ Length (mm) } & \multicolumn{2}{|c|}{425.0} \\
\hline & \multicolumn{2}{|c|}{ Diameter $(\mathrm{mm})$} & \multicolumn{2}{|c|}{10.0} \\
\hline & \multicolumn{2}{|c|}{ Mass $(\mathrm{kg})$} & \multicolumn{2}{|c|}{4} \\
\hline & \multicolumn{2}{|c|}{ Diametral inertia $\left(\mathrm{kg} \cdot \mathrm{m}^{2}\right)$} & \multicolumn{2}{|c|}{0.0046} \\
\hline & \multicolumn{2}{|c|}{ Polar inertia $\left(\mathrm{kg} \cdot \mathrm{m}^{2}\right)$} & \multicolumn{2}{|c|}{0.00786} \\
\hline \multirow{2}{*}{ Disk } & \multicolumn{2}{|c|}{ Diameter $(\mathrm{mm})$} & \multicolumn{2}{|c|}{74.0} \\
\hline & \multicolumn{2}{|c|}{ Thickness (mm) } & \multicolumn{2}{|c|}{25.0} \\
\hline $\begin{array}{l}\text { The sliding } \\
\text { bearing }\end{array}$ & \multicolumn{2}{|c|}{$\begin{array}{l}\text { Stiffness coefficients } \\
\quad\left(\mathrm{MN} \cdot \mathrm{m}^{-1}\right)\end{array}$} & \multicolumn{2}{|c|}{$\begin{array}{l}\text { Damping coefficients } \\
\left(\mathrm{kN} \cdot \mathrm{s} \cdot \mathrm{m}^{-1}\right)\end{array}$} \\
\hline \multirow{4}{*}{$\begin{array}{l}\text { The first } \\
\text { bearing }\end{array}$} & $k_{x x}$ & 24.10 & $c_{x x}$ & 71.30 \\
\hline & $k_{x y}$ & -3.19 & $c_{x y}$ & 34.20 \\
\hline & $k_{y x}$ & 72.20 & $c_{y x}$ & 48.30 \\
\hline & $k_{y y}$ & 45.40 & $c_{y y}$ & 55.40 \\
\hline \multirow{4}{*}{$\begin{array}{l}\text { The } \\
\text { second } \\
\text { bearing }\end{array}$} & $k_{x x}$ & 25.80 & $c_{x x}$ & 72.90 \\
\hline & $k_{x y}$ & -3.78 & $c_{x y}$ & 38.00 \\
\hline & $k_{y x}$ & 81.20 & $c_{y x}$ & 52.00 \\
\hline & $k_{y y}$ & 52.60 & $c_{y y}$ & 63.60 \\
\hline
\end{tabular}

gained through identified unbalance forces, the comparison of magnitude and phase is given in Table 2, and the identified unbalance parameters show excellent agreement in magnitude as well as phase with the assumed and the literature's ones. From these discussions, the proposed method can identify the unbalance parameters reliably and effectively; at the same time, this proposed method is also robust to the noise data of measured displacement.

\section{Experimental Example}

It is aimed at gaining the unbalance parameters of a rotorbearing system from the measured displacement response. The test rig considered in this paper shown in Figure 5 is an INV-1612 rotor system by Coinv (China Orient Institute of
Noise \& Vibration). The test rig is driven through a motor which can produce some different speeds and directions. The test rig is composed of a disk and two sliding bearings. There are 16 equally spaced M4-threaded holes at a radius of $30 \mathrm{~mm}$ of the disk. The bearing dynamic parameters of the sliding bearing and the structural parameter of the test rig are listed in Table 3. The transient response in both the horizontal and vertical directions ( $x$ and $y$ ) can be measured by the proximity (displacement) probes mounted in Figure 5. The key-phase signal provides the once-per-revolution signal which serves to locate the angular position of the shaft. And the measured signals are processed by the INV303/306 software. Displacement responses are obtained from the test rig at 2000 rpm, shown in Figure 6.

5.1. Identification of the Unbalance Parameters for the Test Rig. The displacement responses in the time history from the experimental data are used as inputs and the experimental unbalance parameters have been identified. Figure 7 shows the identified unbalance forces by the proposed method. From Figure 7, it can be seen that the time cycle of identified unbalance forces is $0.03 \mathrm{~s}$ consistent with the rotor spin speed of $2000 \mathrm{rpm}$. From Figure 7 and (2), the unbalance parameters are calculated. The magnitude of the unbalance parameters is estimated to be $44.202 \mathrm{~g} \cdot \mathrm{mm}$ and the phase angle is $96^{\circ}$ ahead of the shaft marker. Because the unbalance mass is fixed at $30 \mathrm{~mm}$ radii from the center of the disk, the magnitude of the unbalance parameters is $1.4734 \mathrm{~g}$.

5.2. The Test Rig Balancing. A comparison of the vibration amplitudes before and after balancing proved the usefulness of the proposed method when the actual unbalance parameters are unknown. The unbalance mass of $1.4734 \mathrm{~g}$ is added to the disk in Figure 5. Figure 8 shows the new displacement responses measured in two radial directions with the balance weight fitted. The comparison of displacement responses measured before and after balancing is shown in Figure 8 and 
TABLE 2: Comparison of the unbalance parameters from numerical simulation.

\begin{tabular}{lccc}
\hline $\begin{array}{l}\text { Unbalance } \\
\text { parameters position }\end{array}$ & $\begin{array}{c}\text { Assumed unbalance, } \\
\text { magnitude@phase } \\
\text { (g@degree) }\end{array}$ & $\begin{array}{c}\text { Identified unbalance (from literature [1]), } \\
\text { magnitude@phase } \\
\text { (g@degree) }\end{array}$ & $\begin{array}{c}\text { Identified unbalance, } \\
\text { magnitude@phase } \\
\text { (g@degree) }\end{array}$ \\
\hline Disc1 & $4.50 @ 30$ & $4.42 @ 29.65$ & $4.51 @ 30.05$ \\
Disc2 & $2.20 @ 60$ & $2.18 @ 59.72$ & $2.19 @ 59.84$ \\
\hline
\end{tabular}

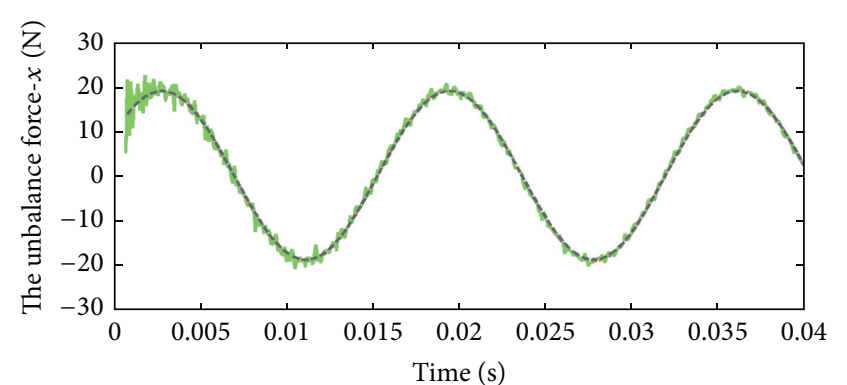

- - - Real force

- Identified force

- - - Force from the literature

(a) The horizontal unbalance force

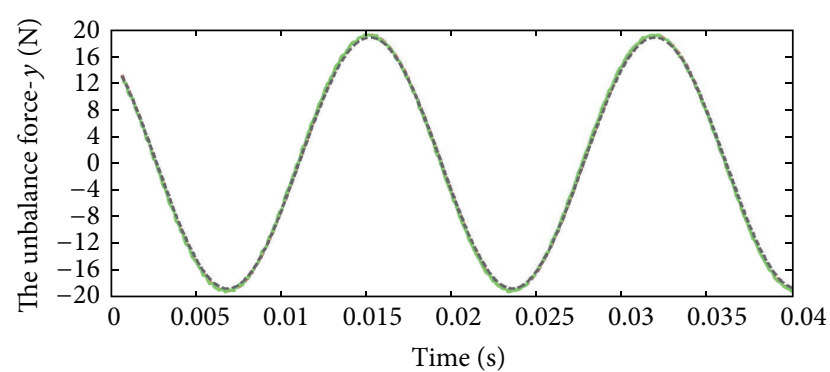

- - - Real force

— Identified force

- - - Force from the literature

(b) The vertical unbalance force

FIgURE 3: The identified unbalance forces on the first disk.
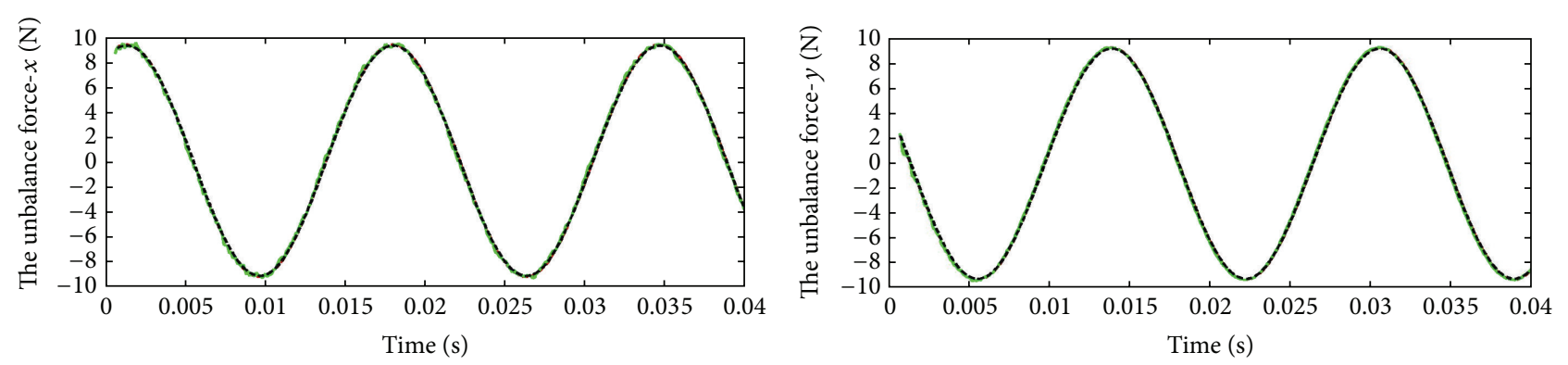

- - - Real force

- Identified force

- - - Force from the literature

- - - Real force

- Identified force

- - - Force from the literature

(a) The horizontal unbalance force

(b) The vertical unbalance force

FIgURE 4: The identified unbalance forces on the second disk.

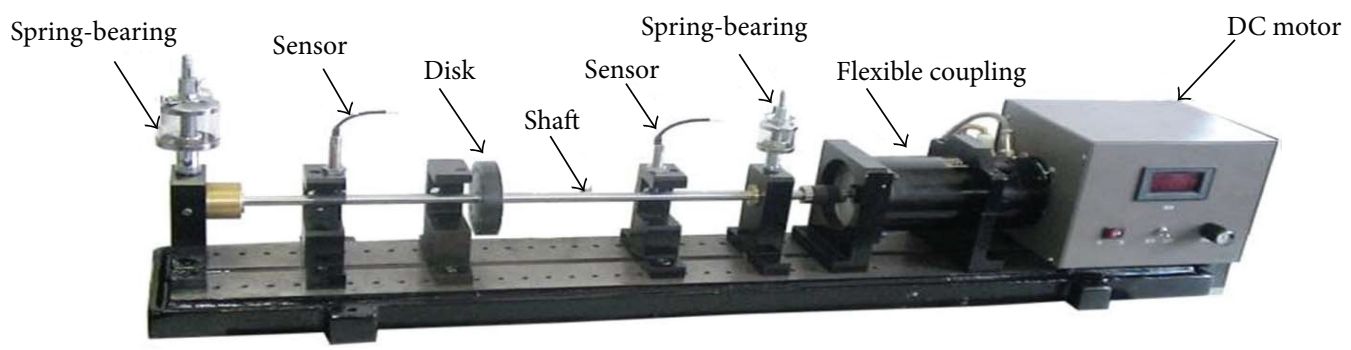

FIGURE 5: The test rig and schematic diagram. 


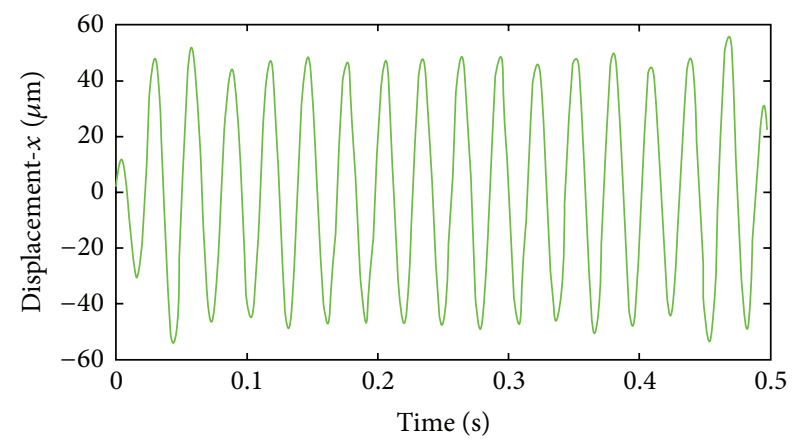

(a) The horizontal displacement response

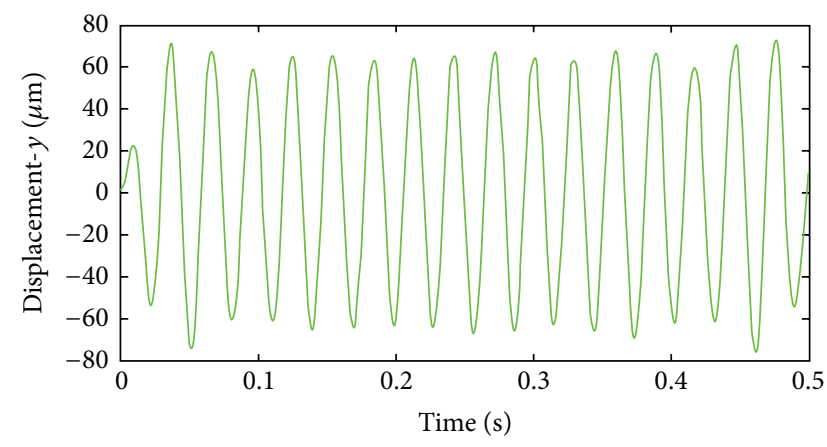

(b) The vertical displacement response

FIGURE 6: Responses at the rotor spin speed of $2000 \mathrm{rpm}$.

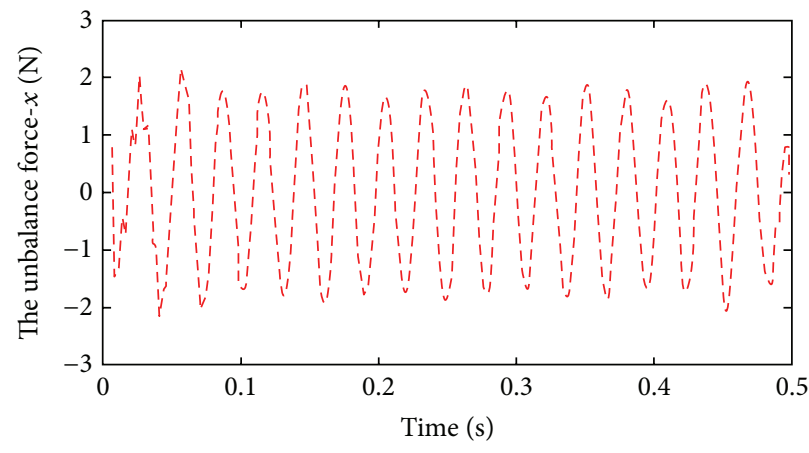

(a) The identified horizontal unbalance force

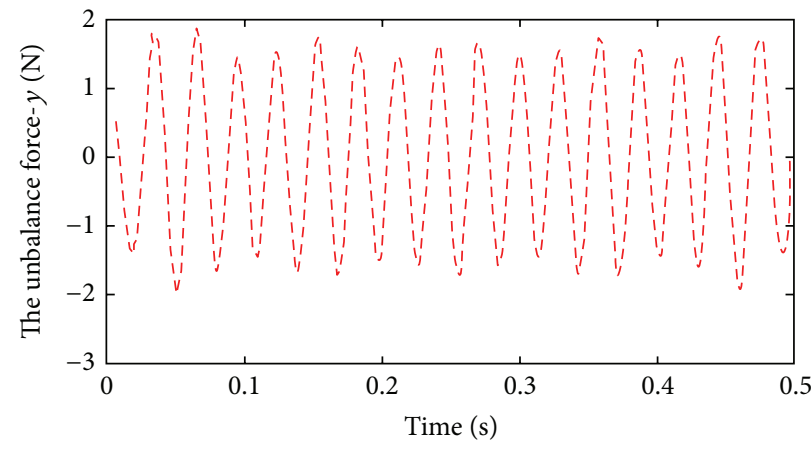

(b) The identified vertical unbalance force

FIGURE 7: The identified unbalance forces of the test rig.

TABle 3: Parameters of the test rig.

\begin{tabular}{|c|c|c|c|c|}
\hline Parts & \multicolumn{2}{|c|}{ Parameters } & \multicolumn{2}{|c|}{ Specifications } \\
\hline & \multicolumn{2}{|c|}{ Length (mm) } & \multicolumn{2}{|c|}{490.0} \\
\hline & \multicolumn{2}{|c|}{ Diameter (mm) } & \multicolumn{2}{|c|}{10.0} \\
\hline Shaft & \multicolumn{2}{|c|}{ Density $\left(\operatorname{kg}\left(\mathrm{m}^{3}\right)^{-1}\right)$} & \multicolumn{2}{|c|}{7850.0} \\
\hline & \multicolumn{2}{|c|}{ Young's modulus (Gpa) } & \multicolumn{2}{|c|}{205.8} \\
\hline & \multicolumn{2}{|c|}{ Poisson ratio } & \multicolumn{2}{|c|}{0.3} \\
\hline \multirow{2}{*}{ Disk } & \multicolumn{2}{|c|}{ Diameter $(\mathrm{mm})$} & \multicolumn{2}{|c|}{80.0} \\
\hline & \multicolumn{2}{|c|}{ Thickness (mm) } & \multicolumn{2}{|c|}{15.0} \\
\hline \multirow[t]{2}{*}{$\begin{array}{l}\text { The sliding } \\
\text { bearing }\end{array}$} & \multicolumn{2}{|c|}{$\begin{array}{l}\text { Stiffness coefficients } \\
\qquad\left(\mathrm{MN} \cdot \mathrm{m}^{-1}\right)\end{array}$} & \multicolumn{2}{|c|}{$\begin{array}{c}\text { Damping coefficients } \\
\left(\mathrm{kN} \cdot \mathrm{s} \cdot \mathrm{m}^{-1}\right)\end{array}$} \\
\hline & $k_{x x}$ & 49.513 & $c_{x x}$ & 200.21 \\
\hline \multirow{3}{*}{$\begin{array}{l}\text { The first } \\
\text { bearing }\end{array}$} & $k_{x y}$ & -29.591 & $c_{x y}$ & 21.507 \\
\hline & $k_{y x}$ & 6.4475 & $c_{y x}$ & 702.16 \\
\hline & $k_{y y}$ & 35.744 & $c_{y y}$ & 272.48 \\
\hline \multirow{4}{*}{$\begin{array}{l}\text { The } \\
\text { second } \\
\text { bearing }\end{array}$} & $k_{x x}$ & 200.021 & $c_{x x}$ & 874.03 \\
\hline & $k_{x y}$ & -69.727 & $c_{x y}$ & 390.64 \\
\hline & $k_{y x}$ & 51.759 & $c_{y x}$ & 361.34 \\
\hline & $k_{y y}$ & 0.1 & $c_{y y}$ & 244.16 \\
\hline
\end{tabular}

Table 4. The horizontal displacement response is attenuated by about $58.85 \%$, and the vertical response is decreased by about $65.76 \%$. The measured displacement responses can be reduced by applying the identified unbalance parameters based on the proposed method.

\section{Conclusions}

An identification method for the unbalance parameters of a rotor-bearing system is proposed. The main advantage of this method is that the states of a few measured points need to be measured only by one test which greatly reduced the number of physical experiments and cost and it is robust to the noise data of measured displacement, which is very critical to the practical situation. And the proposed method can be accurate and effective to obtain the dynamic load determined difficultly by some traditional methods.

\section{Conflict of Interests}

The authors declare that there is no conflict of interests regarding the publication of this paper. 
TABLE 4: Highest amplitude of measured points before and after balancing.

\begin{tabular}{|c|c|c|c|c|c|}
\hline \multicolumn{2}{|c|}{ Highest amplitude- $x / \mu \mathrm{m}$} & \multirow{2}{*}{$\begin{array}{c}\text { The effect of equilibrium } \\
\%\end{array}$} & \multicolumn{2}{|c|}{ Highest amplitude- $y / \mu \mathrm{m}$} & \multirow{2}{*}{$\begin{array}{c}\text { The effect of equilibrium } \\
\%\end{array}$} \\
\hline Before balancing & After balancing & & Before balancing & After balancing & \\
\hline 57.1744 & 23.5264 & 58.85 & 73.8255 & 25.2785 & 65.76 \\
\hline
\end{tabular}

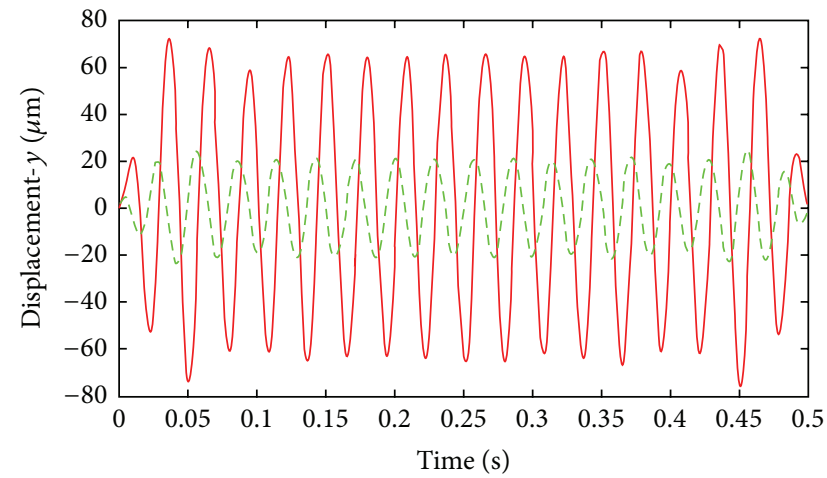

- Before balancing

(a) The vertical displacement response

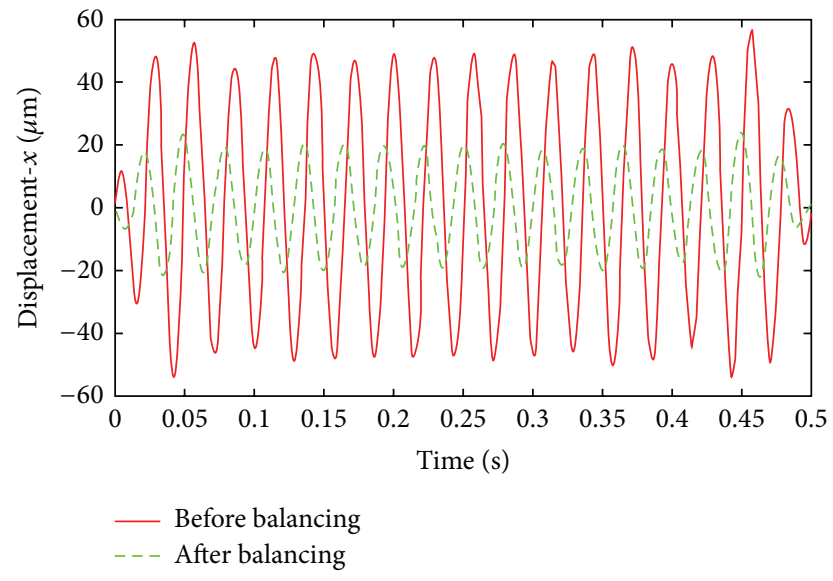

(b) The horizontal displacement response

FIGURE 8: Experimental unbalance responses: before and after the balancing procedure.

\section{Acknowledgments}

The work has been supported by a project supported by Scientific Research Fund of Hunan Provincial Education Department, China (Grant no. 15B057), Specialized Research Fund for the Doctoral Program of Higher Education, China (Grant no. 20130161130001), National Natural Science Foundation of China (Grant nos. 11202076, 11202073), and the Changzhou City Science and Technology Support Program (CE20140027).

\section{References}

[1] R. Tiwari and V. Chakravarthy, "Simultaneous estimation of the residual unbalance and bearing dynamic parameters from the experimental data in a rotor-bearing system," Mechanism and Machine Theory, vol. 44, no. 4, pp. 792-812, 2009.

[2] M. B. Deepthikumar, A. S. Sekhar, and M. R. Srikanthan, "Modal balancing of flexible rotors with bow and distributed unbalance," Journal of Sound and Vibration, vol. 332, no. 24, pp. 6216-6233, 2013.

[3] G. N. D. S. Sudhakar and A. S. Sekhar, "Identification of unbalance in a rotor bearing system," Journal of Sound and Vibration, vol. 330, no. 10, pp. 2299-2313, 2011.

[4] M. Darlow, Balancing of High-Speed Machinery, Springer, New York, NY, USA, 1989.

[5] T. P. Goodman, "A least-squares method for computing balance corrections," Journal of Engineering for Industry, vol. 86, no. 3, pp. 273-277, 1964.

[6] C. D. Untaroiu, P. E. Allaire, and W. C. Foiles, "Balancing of flexible rotors using convex optimization techniques: optimum min-max LMI influence coefficient balancing," Journal of Vibration and Acoustics, vol. 130, no. 2, Article ID 021006, 2008.
[7] F. Han, X. L. Guo, and H. Y. Gao, "Bearing parameter identification of rotor-bearing system based on Kriging surrogate model and evolutionary algorithm," Journal of Sound and Vibration, vol. 332, no. 11, pp. 2659-2671, 2013.

[8] R. Tiwari and V. Chakravarthy, "Simultaneous identification of residual unbalances and bearing dynamic parameters from impulse responses of rotor-bearing systems," Mechanical Systems and Signal Processing, vol. 20, no. 7, pp. 1590-1614, 2006.

[9] S. Edwards, A. W. Lees, and M. I. Friswell, "Experimental identification of excitation and support parameters of a flexible rotor-bearings-foundation system from a single run-down," Journal of Sound and Vibration, vol. 232, no. 5, pp. 963-992, 2000.

[10] K.-Y. Lum, V. T. Coppola, and D. S. Bernstein, "Adaptive autocentering control for an active magnetic bearing supporting a rotor with unknown mass imbalance," IEEE Transactions on Control Systems Technology, vol. 4, no. 5, pp. 587-597, 1996.

[11] M. S. De Queiroz, "An active identification method of rotor unbalance parameters," Journal of Vibration and Control, vol. 15, no. 9, pp. 1365-1374, 2009.

[12] J. M. Varah, "A practical examination of some numerical methods for linear discrete ill-posed problems," SIAM Review, vol. 21, no. 1, pp. 100-111, 1979.

[13] K. Sekuła, C. Graczykowski, and J. Holnicki-Szulc, "On-line impact load identification," Shock and Vibration, vol. 20, no. 1, pp. 123-141, 2013.

[14] X. Sun, J. Liu, X. Han et al., "A new improved regularization method for dynamic load identification," Inverse Problems in Science and Engineering, vol. 22, no. 7, pp. 1741-5977, 2014.

[15] G. Genta, "Consistent matrices in rotor dynamic," Meccanica, vol. 20, no. 3, pp. 235-248, 1985.

[16] H. P. Liu, H. Xu, P. J. Ellison, and Z. Jin, "Application of computational fluid dynamics and fluid-structure interaction 
method to the lubrication study of a rotor-bearing system," Tribology Letters, vol. 38, no. 3, pp. 325-336, 2010.

[17] W. Xiong, Z. Hou, L. Lü et al., "Research on calculation method of stiffness and damping coefficients for hybrid bearings based on dynamic Mesh model," Journal of Mechanical Engineering, vol. 48, no. 23, pp. 118-126, 2012.

[18] Z. Q. Hou, W. L. Xiong, and X. B. Yang, "Study on dynamic characteristics of a hydrostatic and hydrodynamic journal bearings for small diameter grinding spindle," Advanced Materials Research, vol. 497, pp. 99-104, 2012.

[19] W. Mao, X. Han, and G. Liu, "Research on dynamic characteristics of sliding bearing nonlinear oil-film based on fluidstructure interactio," China Mechanical Engineering, vol. 25, no. 3, pp. 383-387, 2014.

[20] G. R. Liu and X. Han, Computational Inverse Technique in Nondestructive Evaluation, CRC Press, 2003.

[21] G. R. Liu, W. B. Ma, and X. Han, "An inverse procedure for identification of loads on composite laminates," Composites Part B: Engineering, vol. 33, no. 6, pp. 425-432, 2002.

[22] L. Wang, X. Han, J. Liu, X. He, and F. Huang, "A new regularization method and application to dynamic load identification problems," Inverse Problems in Science and Engineering, vol. 19, no. 6, pp. 765-776, 2011.

[23] J. Liu, X. Han, C. Jiang, H. M. Ning, and Y. C. Bai, "Dynamic load identification for uncertain structures based on interval analysis and regularization method," International Journal of Computational Methods, vol. 8, no. 4, pp. 667-683, 2011. 


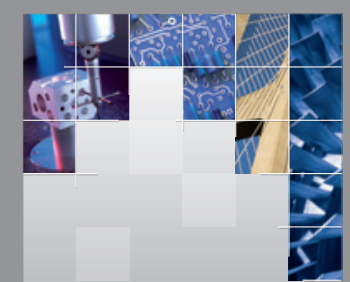

\section{Enfincering}
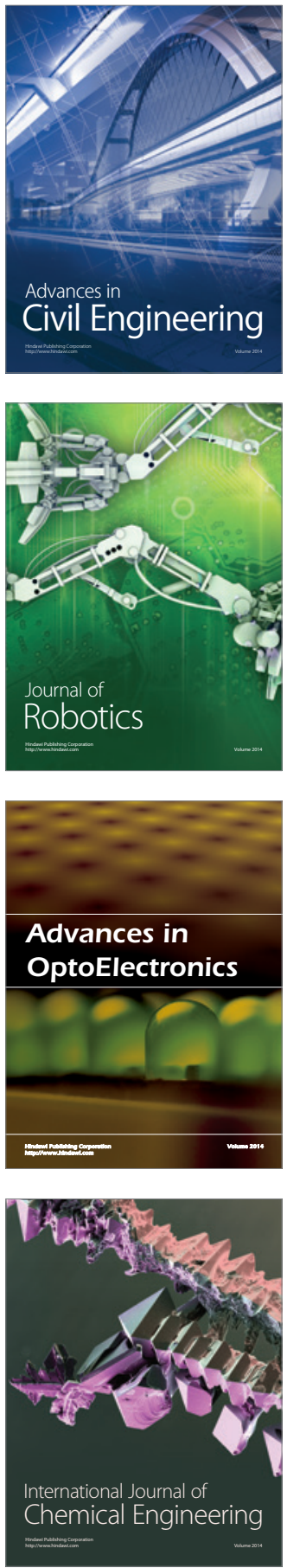

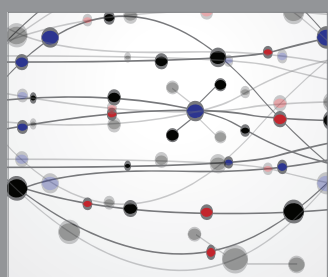

The Scientific World Journal

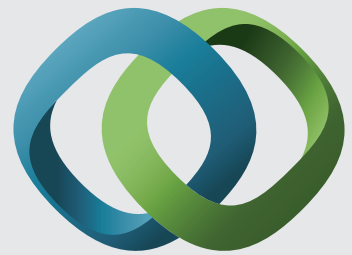

\section{Hindawi}

Submit your manuscripts at

http://www.hindawi.com
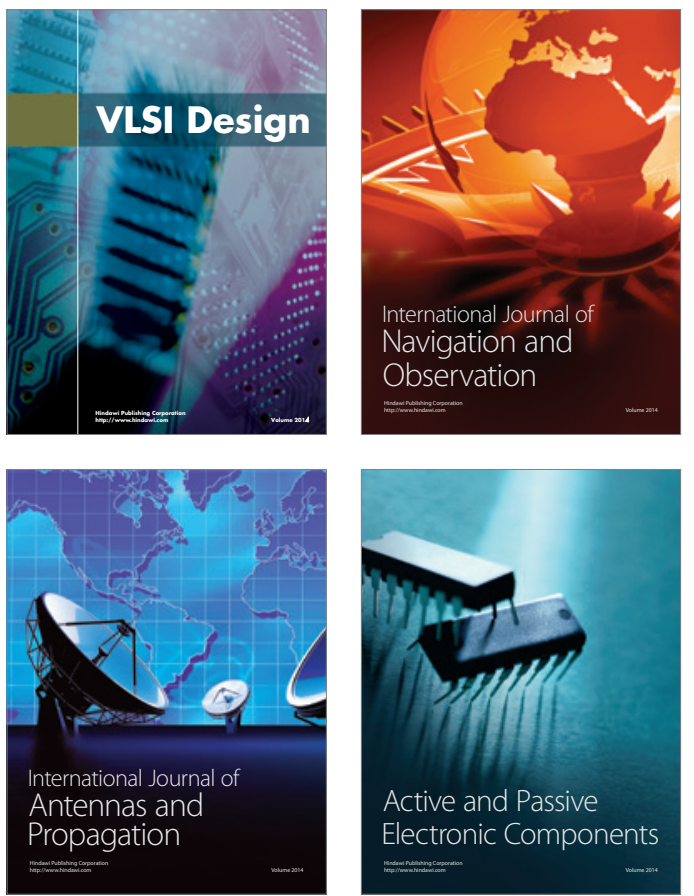
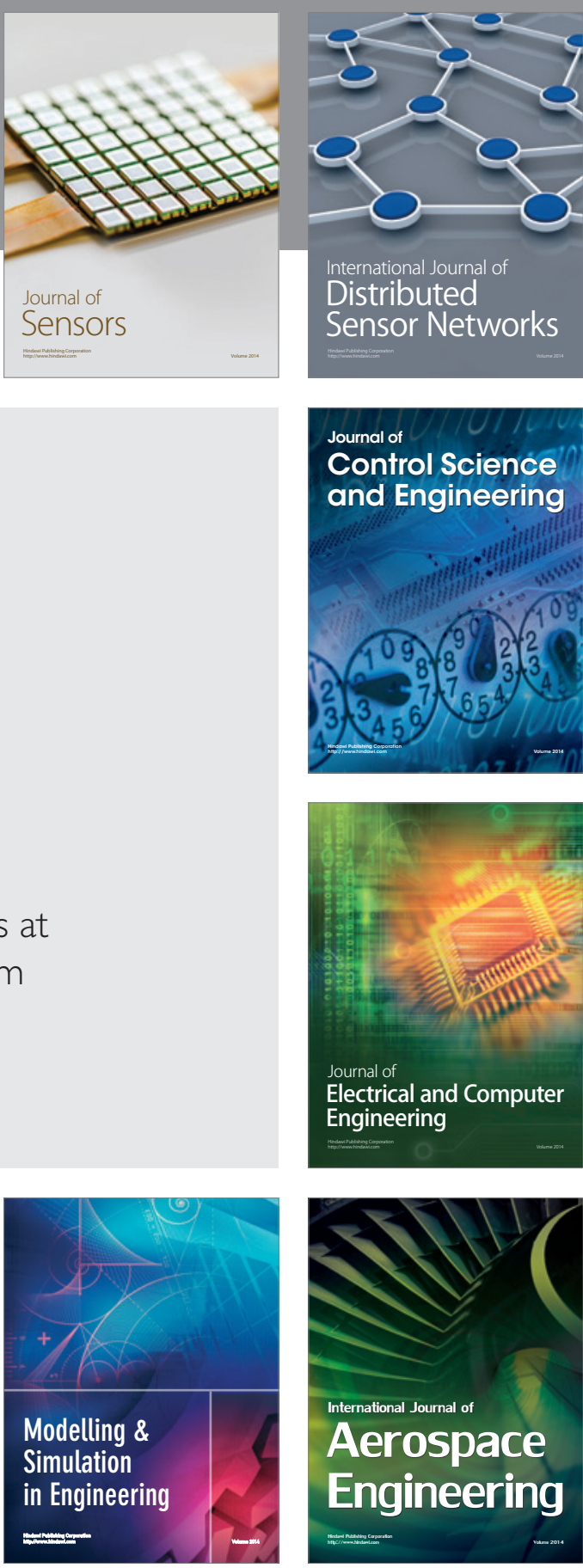

International Journal of

Distributed

Sensor Networks

Journal of

Control Science

and Engineering
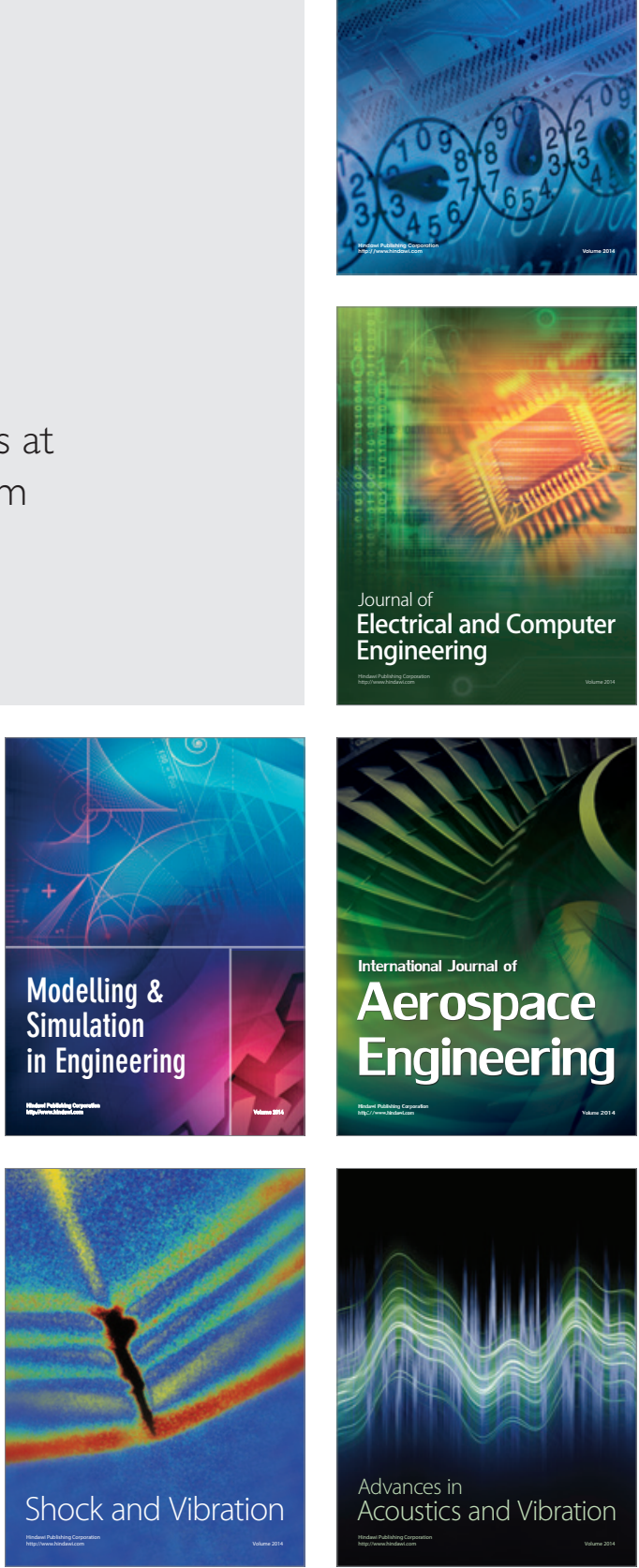